\title{
Boceprevir Plus Peginterferon Alfa-2a/Ribavirin in Treatment-Naïve Hepatitis C Virus Genotype 1 Patients: International Phase IIIb/IV TriCo Trial
}

\author{
Peter Ferenci · Florin A. Caruntu • Gabriella Lengyel • Diethelm Messinger • \\ Georgios Bakalos · Robert Flisiak
}

Received: December 8, 2015 / Published online: May 26, 2016

(C) The Author(s) 2016. This article is published with open access at Springerlink.com

\begin{abstract}
Introduction: Boceprevir was not previously studied with peginterferon alfa-2a/ribavirin in phase III trials in treatment-naïve chronic hepatitis $\mathrm{C}$ patients. The international phase IIIb/IV TriCo study was, therefore, designed to evaluate boceprevir in combination with peginterferon alfa-2a/ribavirin in treatment-naïve genotype 1 patients.
\end{abstract}

On behalf of the TriCo Study Group.

Enhanced content To view enhanced content for this article go to http://www.medengine.com/Redeem/ B3D4F06064AD711D.

Electronic supplementary material The online version of this article (doi:10.1007/s40121-016-0110-5) contains supplementary material, which is available to authorized users.

P. Ferenci $(\bowtie)$

Department of Internal Medicine III,

Gastroenterology and Hepatology, Medical

University of Vienna, Vienna, Austria

e-mail: peter.ferenci@meduniwien.ac.at

F. A. Caruntu

National Institute for Infectious Diseases 'Matei

Bals', Bucharest, Romania

G. Lengyel

2nd Department of Medicine, Semmelweis

University, Budapest, Hungary
Methods: A total of 165 treatment-naïve genotype 1 patients were assigned to boceprevir plus peginterferon alfa-2a/ribavirin therapy according to the label. All patients received a 4-week lead-in with peginterferon alfa-2a/ribavirin, after which boceprevir (2400 mg/day) was introduced. The total duration of treatment ranged from 28 to 48 weeks depending on the virological response at Weeks 4,8 , and 24 , and on fibrosis status. The primary efficacy outcome was sustained virological response (SVR) [undetectable hepatitis $\mathrm{C}$ virus (HCV) ribonucleic acid (RNA) 12 weeks after actual end of treatment, SVR12].

Results: The overall SVR12 rate was 81\% (133/ 165 , 95\% confidence interval 74-86\%). After 8 weeks of treatment, $61 \%$ of patients had

\section{Messinger}

PROMETRIS GmbH, Mannheim, Germany

G. Bakalos

F. Hoffmann-La Roche Ltd, Basel, Switzerland

R. Flisiak

Department of Infectious Diseases and Hepatology, Medical University of Białystok, Białystok, Poland 
undetectable HCV RNA, and 78 patients (47\%) had an early response (undetectable HCV RNA at Weeks 8 and 24) and were eligible to stop all therapy at Week 28. Among early responders the SVR12 rate was 95\% (74/78), and among patients with cirrhosis assigned to 48 weeks' treatment, the SVR12 rate was $67 \%(14 / 21)$. The overall relapse rate was $7 \%(10 / 143)$, and was $4 \%$ (3/77) among early responders. The most common adverse events were anemia (41\%), neutropenia (32\%), and dysgeusia (31\%).

Conclusion: High SVR12 rates can be achieved with boceprevir plus peginterferon alfa-2a/ ribavirin in treatment-naïve $\mathrm{HCV}$ genotype 1 patients, including patients with well-compensated cirrhosis. Treatment is well tolerated when label restrictions are taken into account.

Trial Registration Number: ClinicalTrials.gov Identifier: NCT01591460.

Funding: F. Hoffmann-La Roche Ltd.

Keywords: Boceprevir; Chronic hepatitis C; Peginterferon alfa-2a; Ribavirin; Sustained virological response

\section{INTRODUCTION}

There are now several direct-acting antiviral agents (DAAs) from multiple classes available for the treatment of chronic hepatitis C [1-7]. In general, both interferon-free and interferon-containing DAA regimens increase sustained virological response (SVR) rates and allow for shorter treatment durations when compared with dual peginterferon/ribavirin therapy [1-7]. Access to these newer agents and combinations is restricted by the application of rigid patient selection criteria in most settings [2]. Dual peginterferon/ribavirin therapy is no longer recommended for genotype 1 patients by the European Association for the Study of Liver (EASL) and, as evidence of the rapid evolution of the field, boceprevir-based triple therapy is also not recommended unless more efficacious regimens are unavailable [4].

Boceprevir was the first DAA approved for use in patients with chronic hepatitis C [8]. It is only indicated for use in combination with peginterferon/ribavirin in patients with hepatitis $\mathrm{C}$ virus (HCV) genotype 1 infection and well-compensated liver disease [8]. Treatment for 48 weeks with the combination of boceprevir plus peginterferon alfa-2b/ ribavirin produced an overall SVR rate (defined as undetectable $\mathrm{HCV}$ ribonucleic acid [RNA] levels for 24 weeks after the completion of therapy) of $66 \%$ in treatment-naïve patients in a large international registration trial (clinicaltrials.gov NCT01591460) [9]. However, the drug was not studied in combination with peginterferon alfa-2a/ribavirin during phase III trials in treatment-naïve patients. To fill this knowledge gap, we conducted an international, multicenter, open-label, phase IIIb/IV trial to evaluate the efficacy and safety of boceprevir plus peginterferon alfa-2a/ribavirin in treatment-naïve patients with HCV genotype 1 chronic hepatitis C.

\section{METHODS}

\section{Patients}

Eligible patients were aged 18 years or older, had chronic hepatitis C, quantifiable HCV RNA in serum and HCV genotype 1 infection, and had not received prior treatment with any interferon-based therapy or any DAA. Patients with cirrhosis were required to have compensated liver disease (Child-Pugh score $\leq 6$ ). 
Patients with evidence of hepatitis A or B infection or human immunodeficiency virus infection were excluded, as were patients infected with HCV non-1 genotypes and those with a history or evidence of liver disease attributable to a cause other than chronic hepatitis C.

\section{Study Design}

Eligible patients received dual peginterferon alfa-2a/ribavirin during a 4-week lead-in phase, and then triple combination therapy (boceprevir plus peginterferon alfa-2a/ ribavirin) was administered from treatment Weeks 5 to 28 inclusive in an outpatient setting (Supplementary figure 1). The total duration of therapy was determined by cirrhosis status and the on-treatment response.

Non-cirrhotic patients received a response-guided therapy regimen, the length of which was based on the virological response at Weeks 4, 8, and 24. Patients with undetectable HCV RNA (Roche COBAS ${ }^{\circledR}$ $\operatorname{TaqMan}^{\circledR} \quad 2.0$ HCV Test, Roche Molecular Diagnostics, Pleasanton, CA, USA) at Weeks 8 and 24 stopped all therapy at Week 28. Patients with detectable HCV RNA at Week 8 and undetectable HCV RNA at Week 24 continued triple combination therapy until Week 36, at which time boceprevir (Victrelis ${ }^{\circledR}$, Merck \& Co., Inc., Whitehouse Stations, NJ, USA) was discontinued, but dual peginterferon alfa-2a/ ribavirin therapy was continued to Week 48 . Patients with poor interferon responsiveness during the lead-in phase, defined as a $<1-\log _{10}$ $\mathrm{IU} / \mathrm{mL}$ decline in HCV RNA at Week 4, were recommended to receive triple combination therapy from Weeks 5 to 48. Patients with cirrhosis received triple combination therapy from Weeks 5 to 48. All treatment was to be stopped in patients who met the criteria for the predefined futility rules (HCV RNA $\geq 100 \mathrm{IU} / \mathrm{mL}$ at Week 12, or detectable HCV RNA at Week 24).

Subcutaneous peginterferon alfa-2a (Pegasys ${ }^{\circledR}$, Roche, Basel, Switzerland) was administered at a dosage of $180 \mu \mathrm{g} /$ week. Oral ribavirin (Copegus ${ }^{\circledR}$, Roche) was administered at a dosage of 1000 (body weight $<75 \mathrm{~kg}$ ) or $1200 \mathrm{mg} /$ day ( $\geq 75 \mathrm{~kg}$ ) in two divided doses, and oral boceprevir was administered at a dosage of $800 \mathrm{mg}$ three times daily (i.e., every 7-9 h). The dose of peginterferon alfa-2a and/or ribavirin could be reduced in cases of adverse events (AEs) or laboratory abnormalities. Dose reductions of boceprevir were not recommended.

\section{Outcomes}

The primary efficacy variable was SVR12 defined as undetectable HCV RNA (Roche COBAS TaqMan 2.0 HCV Test, [lower limit of detection for genotype $110-15 \mathrm{IU} / \mathrm{mL}$, lower limit of quantification $25 \mathrm{IU} / \mathrm{mL}]$ ) after 12 weeks of untreated follow-up ( $\geq 70$ days after actual end of treatment [EOT]). SVR12 is considered to be equivalent to SVR 24 by regulatory authorities and in current treatment guidelines [1, 4, 10]. Patients without an HCV RNA test result $\geq 70$ days after EOT were assumed not to have achieved an SVR12.

Virological rebound was defined as an increase in HCV RNA by $1-\log _{10}$ from nadir in a patient whose on-treatment HCV RNA level remained $\quad>1000 \mathrm{IU} / \mathrm{mL}$. Virological breakthrough was defined as occurrence of an HCV RNA level $>1000 \mathrm{IU} / \mathrm{mL}$ during treatment after achievement of undetectable HCV RNA. Relapse was defined as detectable HCV RNA during follow-up in a patient with undetectable HCV RNA at EOT. Patients without an HCV RNA test result after EOT 
response were excluded from relapse rate calculations.

Safety was assessed by AE reports, physical and laboratory evaluations, and dosage adjustments and drug discontinuations.

\section{Statistical Analysis}

As this was an exploratory study, no formal hypothesis testing was involved. A sample size of approximately 150 patients was estimated to provide sufficient precision to assess the SVR rate in relation to that achieved with dual combination therapy (peginterferon alfa/ ribavirin) and triple combination therapy comprised a DAA plus peginterferon alfa/ ribavirin. This estimation was made on the basis of the SVR rate achieved with boceprevir plus peginterferon alfa-2b/ribavirin in a previous clinical trial (64-70\%) which would provide a two-sided 95\% confidence interval (CI) of $\pm 8 \%$ [9]. The statistical analysis was performed with SAS version 8.2 and 9.2 (SAS Institute Inc., Cary, NC, USA).

\section{Compliance with Ethics Guidelines}

All procedures followed were in accordance with the ethical standards of the responsible committee on human experimentation (institutional and national) and with the Helsinki Declaration of 1964. Informed consent was obtained from all patients for being included in the study.

\section{RESULTS}

A total of 165 patients were enrolled in Austria, Germany, Hungary, Poland, Romania, and Spain; the majority of patients were enrolled from Eastern European countries (70\%). All 165 patients received at least one dose of study medication and were included in the efficacy analysis (Fig. 1). The first patient was enrolled in July 2012 and the last patient completed follow-up in June 2014. The mean age was 46 years, the mean body mass index was $26 \mathrm{~kg} /$ $\mathrm{m}^{2}, 50 \%$ of the patients were male, and a majority were Caucasian (99\%), infected with HCV genotype $1 \mathrm{~b}(86 \%)$, and had a host IL28B non-CC genotype (79\%) (Table 1).

A total of 14 patients $(8.5 \%)$ had protocol deviations: two patients had contraindications to treatment; nine patients received a dosing regimen that differed from the recommendations for response-guided therapy in the protocol; two patients received less than the recommended initial dose of boceprevir ( $<2400 \mathrm{mg} /$ day); one patient did not receive boceprevir and did not have a post-baseline HCV RNA test result.

All treatment was discontinued prematurely in $26(16 \%)$ patients (Fig. 1). Of note, discontinuation for lack of efficacy at Weeks 12 or 24 occurred in 10 patients overall. A further six patients (4\%) did not complete 24 weeks of follow-up.

\section{Efficacy}

A total of 12 patients (7\%) had a virological response by the end of the 4-week lead-in phase, and 100 (61\%) and 143 (87\%) of patients had undetectable HCV RNA after 4 (Week 8) and 12 (Week 16) weeks of triple therapy, respectively (Fig. 2).

The overall SVR12 rate was $81 \%(133 / 165$, CI 74-86\%) (Fig. 3a). Among patients with HCV genotype $1 \mathrm{a}$ and $1 \mathrm{~b}$ infection, the SVR12 rates were $86 \%(19 / 22$, CI $65-97 \%)$ and $80 \%$ (114/142, CI 73-86\%), respectively, and among patients with host IL28B CC, CT, and 


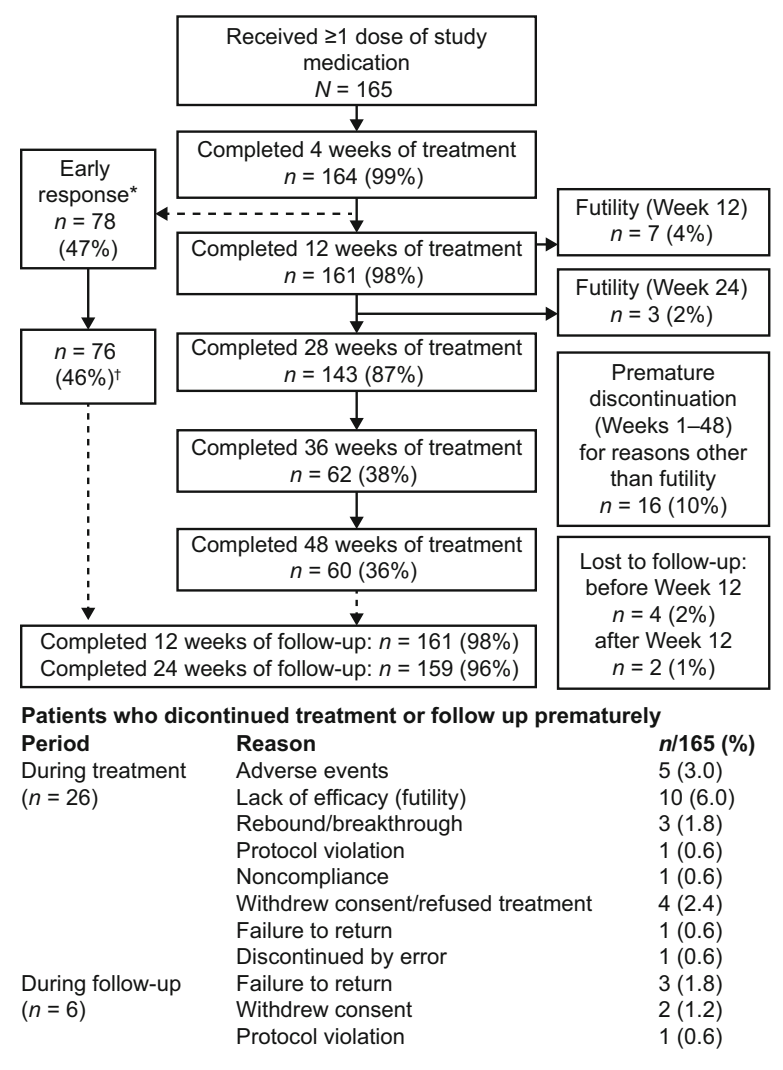

Fig. 1 Patient disposition and reason for premature withdrawal from treatment or follow-up. Asterisk early response is defined as patients with undetectable $\mathrm{HCV}$ RNA at week $8, \mathrm{HCV}$ RNA $<100 \mathrm{IU} / \mathrm{mL}$ at week 12 and undetectable HCV RNA at week 24, excluding cirrhotics and poor responders. Dagger early responders had to stop all therapy at Week 28.76 of 78 early responder patients completed 28 weeks of treatment with all drugs. One individual discontinued boceprevir and ribavirin at Study Day 70 due to an adverse event and subsequently refused further treatment with peginterferon alfa-2a at Study Day 162. A second individual refused further treatment with peginterferon alfa-2a at Day Study 162 and subsequently with ribavirin and boceprevir at Study Day 168. HCV bepatitis $C$ virus, RNA ribonucleic acid

TT genotypes the SVR12 rates were 94\% (33/ 35 , CI $81-99 \%), 77 \%$ (71/92, CI 67-85\%), and 78\% (29/37, CI 62-90\%), respectively (Supplementary figure 2).

A total of 78 non-cirrhotic patients $(47 \%)$ had an early response (undetectable HCV RNA at Weeks 8 and 24) and were eligible to stop all therapy at Week 28. Among these patients, the SVR12 rate was 95\% (74/78, CI 87-99\%). A further 24 patients had a late response (detectable HCV RNA at Week 8, undetectable HCV RNA at Week 24) of whom 21 (88\%, CI 68-97\%) had an SVR12. Among those patients with a poor response $\left(<1-\log _{10}\right.$ decrease in HCV RNA) at the end of the 4-week lead-in phase, the SVR12 rate was 75\% (18/24, CI 53-90\%), and among all patients with cirrhosis the SVR12 rate was $67 \%(14 / 21$, CI 43-85\%). The baseline characteristics of patients with an early and late response are shown in Supplementary Table 1. The characteristics in these two groups were generally similar with the exception of a higher prevalence of a host IL28B CC genotype in early responders (31\% versus $8 \%$ in late responders) and a lower proportion of patients with a high baseline HCV RNA level in early responders (69\% versus $88 \%$, respectively).

The overall relapse rate was $7 \%(10 / 143)$ (CI 3-12\%) (Fig. 3b). All patients who relapsed harbored HCV genotype $1 \mathrm{~b}$ and had a non-CC genotype (eight CT and two TT). Among patients with an early and late response the relapse rates were $4 \%$ and $9 \%$, respectively, and among patients with cirrhosis the relapse rate was $13 \%$.

A $\geq 3-\log _{10}$ decrease in serum HCV RNA after 4 weeks of triple therapy (Week 8) was associated with both a positive predictive value and negative predictive value of $86 \%$ for SVR (Supplementary figure 3).

Rebound, defined as $1-\log _{10}$ increase above nadir, was observed in $6 \%(10 / 164)$ of patients with an on-treatment decrease in HCV RNA, and breakthrough was observed in 3\% (4/151) of patients with an on-treatment virological response. 
Table 1 Baseline demographic and disease characteristics

\begin{tabular}{|c|c|}
\hline Characteristic & $\begin{array}{l}\text { All treated patients, } \\
N=165\end{array}$ \\
\hline Male gender, $n(\%)$ & $82(50)$ \\
\hline Mean age $\pm S D$ (range), years & $45.8 \pm 12.5(18-72)$ \\
\hline $\begin{array}{l}\text { Mean body weight } \pm \text { SD (range), } \\
\mathrm{kg}\end{array}$ & $\begin{array}{r}75.9 \pm 16.7 \\
(46-130)\end{array}$ \\
\hline $\begin{array}{l}\text { Mean body mass index } \pm \mathrm{SD} \\
\quad \text { (range), } \mathrm{kg} / \mathrm{m}^{2}\end{array}$ & $\begin{array}{l}25.9 \pm 4.6 \\
\quad(16.7-45.0)\end{array}$ \\
\hline \multicolumn{2}{|l|}{ Race, $n(\%)$} \\
\hline Caucasian/White & $163(99)$ \\
\hline Asian/Oriental & $2(1)$ \\
\hline \multicolumn{2}{|l|}{ Country, $n(\%)$} \\
\hline Austria & $21(13)$ \\
\hline Germany & $8(5)$ \\
\hline Hungary & $31(19)$ \\
\hline Poland & $45(27)$ \\
\hline Romania & $39(24)$ \\
\hline Spain & $21(13)$ \\
\hline \multicolumn{2}{|l|}{ HCV genotype 1 subtype, $n$ (\%) } \\
\hline $1 \mathrm{a}$ & $22(13)$ \\
\hline $1 b$ & $142(86)$ \\
\hline Subtype not determined & $1(<1)$ \\
\hline \multicolumn{2}{|c|}{ Host $I L 28 B$ genotype (rs12979860), $n(\%)$} \\
\hline $\mathrm{CC}$ & $35(21)$ \\
\hline $\mathrm{CT}$ & $92(56)$ \\
\hline TT & $37(22)$ \\
\hline $\begin{array}{l}\text { Mean HCV RNA level } \pm \text { SD } \\
\text { (range), } \log _{10} \mathrm{IU} / \mathrm{mL}\end{array}$ & $6.3 \pm 0.7(2.4-7.5)$ \\
\hline $\begin{array}{l}\mathrm{HCV} \mathrm{RNA}>8,00,000 \mathrm{IU} / \mathrm{mL} \\
\quad n(\%)\end{array}$ & $127(77)$ \\
\hline \multicolumn{2}{|c|}{ Patients with fibrosis assessment, $n$ (\%) } \\
\hline Liver biopsy & $51(31)$ \\
\hline Noninvasive assessment & $121(73)$ \\
\hline
\end{tabular}

Table 1 continued

\begin{tabular}{ll}
\hline Characteristic & $\begin{array}{l}\text { All treated patients, } \\
N=\mathbf{1 6 5}\end{array}$ \\
\hline $\begin{array}{l}\text { Patients with bridging } \\
\text { fibrosis/cirrhosis, } n(\%)^{*}\end{array}$ & $31 / 165(19)$ \\
\hline
\end{tabular}

$S D$ standard deviation, $H C V$ hepatitis $\mathrm{C}$ virus, $R N A$ ribonucleic acid

* Cirrhosis or bridging fibrosis reported as "cirrhosis or transition to cirrhosis". Only patients with a fibrosis assessment are included in calculations. In two patients "cirrhosis" was reported both on liver biopsy and noninvasive assessment (liver elastography)

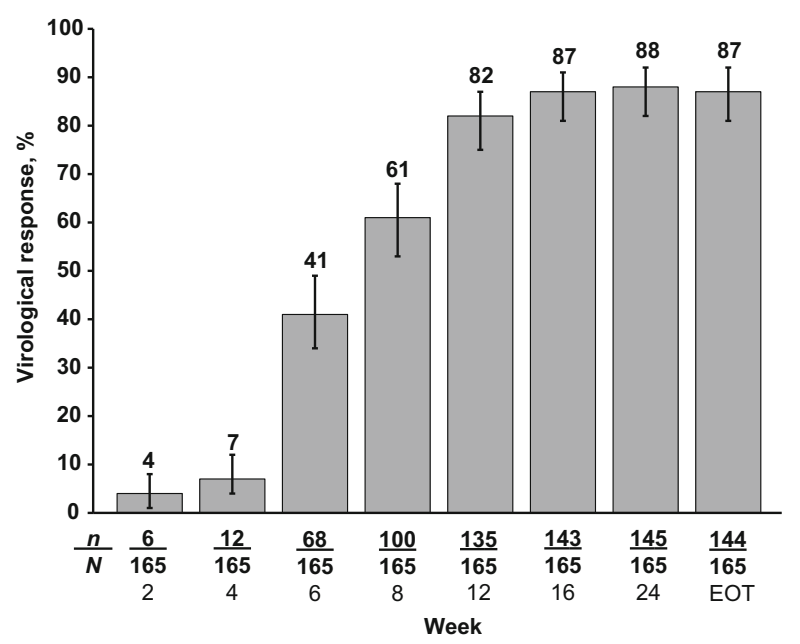

Fig. 2 Virological response over time. Virological response is defined as undetectable HCV RNA (Roche COBAS TaqMan ${ }^{\circledR} 2.0 \mathrm{HCV}$ Test). EOT end of treatment, $H C V$ hepatitis $\mathrm{C}$ virus; $R N A$ ribonucleic acid

\section{Safety}

A total of 18 serious AEs (SAEs) were reported in 15 patients (13 of 18 SAEs were considered to be related to study treatment in the investigator's opinion), and 5 (3\%) patients discontinued treatment for AEs (Table 2). Discontinuation of peginterferon alfa-2a, ribavirin, and boceprevir was attributed to neutropenia in 1,1 , and 4 patients, respectively, and to anemia in 0,2 , 

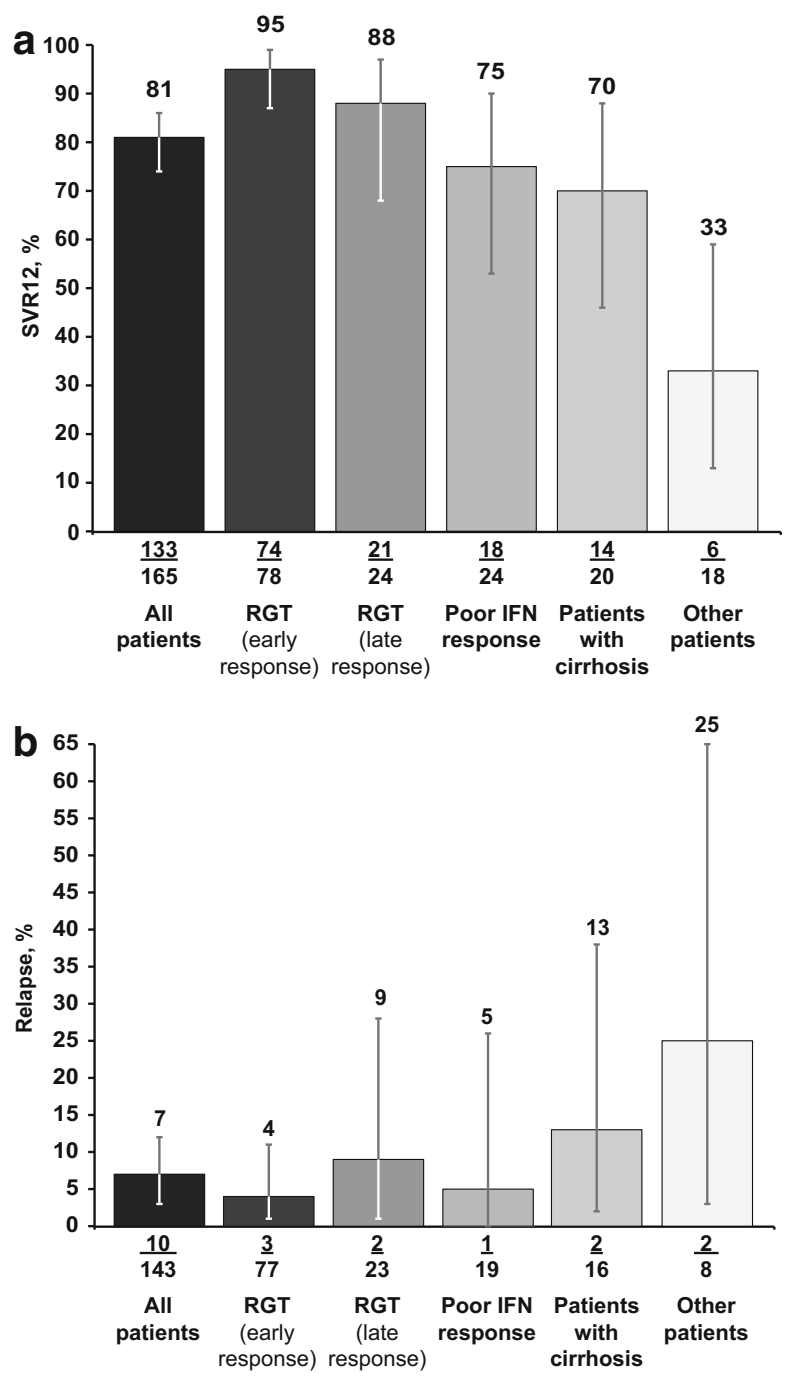

and 3 patients, respectively. A total of 10 patients $(6 \%)$ received treatment with a hematopoietic stimulant (epoetin) and a total of 14 patients $(8 \%)$ received treatment with a colony-stimulating factor. A total of five patients received transfusions of whole blood or packed red blood cells for anemia during the study.

The incidence of individual AEs was similar in the overall study population and in patients with cirrhosis (Table 2). However, when compared with the overall study population, the incidence of SAEs was higher in cirrhotic patients as was the incidence of study drug
4Fig. 3 SVR12 weeks after end of treatment (a) and relapse (b). "Other" includes: one patient who did not stop treatment after fulfillment of futility rules; five patients who should have completed all therapy at Week 28 , but instead received dual peginterferon alfa-2a/ ribavirin until Week 48; two patients who started boceprevir later than specified in the protocol (Study Days 54 and 43 rather than Study Day 29); six patients who discontinued treatment prematurely for reasons not related to futility rules and in whose cases information required to assign these patients to a response-guided therapy category is missing; and four patients who discontinued treatment prematurely according to futility rules and in whose cases information required to assign these patients to a response-guided therapy category is missing. Data for sustained virological response 24 weeks after end of treatment (SVR24) are not shown, but were almost identical to those for SVR12; only one patient who achieved an SVR12 did not achieve an SVR24 (due to missing data at week 24). IFN interferon, $R G T$ response-guided therapy; $S V R$ sustained virological response

discontinuation for AEs and of certain laboratory abnormalities (low hemoglobin concentrations and platelet count) (Table 2). Of note, the incidence of thrombocytopenia was $12 \%$ overall (20/165), but was $33 \%(7 / 21)$ in patients with cirrhosis. Consistent with this observation, a higher proportion of cirrhotic patients had platelet counts of $<50 \times 10^{9} / \mathrm{L}$ $(48 \%$ versus $8 \%$ in the overall study population).

\section{DISCUSSION}

The SVR12 rate observed in treatment-naïve patients treated with boceprevir plus peginterferon alfa-2a/ribavirin in this study was $81 \%$ overall. An overall SVR24 rate of $66 \%$ was previously achieved with a 48-week fixed-duration regimen of boceprevir plus peginterferon alfa-2b/ribavirin in a large, randomized international registration trial (SPRINT-2, ClinicalTrials.gov Identifier: 
Table 2 Adverse events and laboratory abnormalities overall and in patients with cirrhosis

\begin{tabular}{|c|c|c|}
\hline Event & $\begin{array}{l}\text { Overall incidence } \\
n / 165(\%)\end{array}$ & $\begin{array}{l}\text { Incidence in patients } \\
\text { with cirrhosis, } n / 21(\%)\end{array}$ \\
\hline Patients with serious adverse events, $n$ (\%) & $15(9)$ & $7(33)$ \\
\hline Total number of serious adverse events, $n$ & 18 & 8 \\
\hline Discontinuation of all treatment for AEs, $n$ (\%) & $5(3)$ & $3(14)$ \\
\hline \multicolumn{3}{|l|}{ Incidence of individual adverse events* (\%) } \\
\hline Anemia & $67(41)$ & $9(43)$ \\
\hline Neutropenia & $53(32)$ & $5(24)$ \\
\hline Dysgeusia & $51(31)$ & $6(29)$ \\
\hline Asthenia & $47(28)$ & $7(33)$ \\
\hline Influenza-like illness & $40(24)$ & $6(29)$ \\
\hline Fatigue & $35(21)$ & $4(19)$ \\
\hline Cough & $34(21)$ & $3(14)$ \\
\hline Headache & $34(21)$ & $2(10)$ \\
\hline Pruritus & $34(21)$ & $4(19)$ \\
\hline Nausea & $26(16)$ & $3(14)$ \\
\hline Pyrexia & $26(16)$ & - \\
\hline \multicolumn{3}{|l|}{ Laboratory abnormalities (lowest value) $n(\%)$} \\
\hline Hemoglobin $85-<100 \mathrm{~g} / \mathrm{L}$ & $44(27)$ & $6(29)$ \\
\hline Hemoglobin $<85 \mathrm{~g} / \mathrm{L}$ & $16(10)$ & $5(24)$ \\
\hline Neutrophils $0.5-<0.75 \times 10^{9} / \mathrm{L}$ & $40(24)$ & $4(19)$ \\
\hline Neutrophils $<0.5 \times 10^{9} / \mathrm{L}$ & $27(16)$ & $4(19)$ \\
\hline Platelets $20-<50 \times 10^{9} / \mathrm{L}$ & $12(7)$ & $9(43)$ \\
\hline Platelets $<20 \times 10^{9} / \mathrm{L}$ & $1(<1 \%)$ & $1(5)$ \\
\hline ALT $>5-10 \times$ upper limit of normal & $3(2)$ & $1(5)$ \\
\hline
\end{tabular}

AEs adverse events, ALT alanine aminotransferase

${ }^{*}$ Incidence $\geq 15 \%$

NCT00705432) [9]. A direct comparison of the two trials is not possible, because the present trial included only patients from Central and Eastern Europe, whereas the SPRINT-2 trial included a substantial subgroup of Black patients (15\%). Moreover, a higher proportion of patients in SPRINT-2 were infected with HCV genotype $1 \mathrm{a}$ (64\% versus $13 \%$ in the present study). The SVR rate was lower in Black (53\%) than non-Black patients (68\%) in SPRINT-2 [9]. The frequency of important baseline characteristics predictive of SVR was similar in the present study and in the non-Black cohort in SPRINT-2 (19\% and $12 \%$ of patients had bridging cirrhosis/cirrhosis, respectively, 77\% and $84 \%$ of patients had a baseline HCV RNA 
$>800,000 \mathrm{IU} / \mathrm{mL}$, respectively, and the mean ages were 46 and 49 years, respectively) [9].

Approximately one-half (47\%) of patients enrolled in the present study had an early response, defined as undetectable HCV RNA at Weeks 8 and 24 of treatment. These patients were eligible to stop all therapy at Week 28, and importantly, all but two of these individuals completed the full 28-week regimen. The overall SVR12 rate in these individuals was $95 \%$, which is comparable to that achieved with interferon-free DAA-containing regimens that are approved for use in patients with chronic HCV [1-7]. These results are important because access to interferon-free regimens is limited to patients who meet specific and restricted criteria in many jurisdictions [11].

The overall SVR rate of $81 \%$ achieved with boceprevir plus peginterferon alfa-2a in the present study is comparable to SVR rates achieved in large Phase III studies of simeprevir-based triple therapy (QUEST-1, ClinicalTrials.gov Identifier: NCT01289782; QUEST-2, ClinicalTrials.gov Identifier: NCT01290679) [12, 13], and faldaprevir-based triple therapy (StartVerso-1, ClinicalTrials.gov Identifier: NCT01343888) (80-81\%) [14]. It is not possible to draw any firm conclusions regarding the comparative efficacy of the different regimens used in these trials or between the present study and the phase III study by Poordad et al. [9].

Consistent with previous studies, anemia occurred frequently during boceprevir-based triple therapy. In the present study, a total of $41 \%$ of patients experienced anemia as an $\mathrm{AE}$, $27 \%$ of patients had a hemoglobin concentration $<100 \mathrm{~g} / \mathrm{L}$ during treatment, and three patients discontinued treatment with boceprevir due to anemia. The incidence of anemia in the present study was similar to that reported in boceprevir recipients by Poordad et al. (49\%); however, use of erythropoietin to treat anemia was less common in the present study than in the study by Poordad et al. (6\% versus 43\%) [9].

Patients with cirrhosis are a particularly important subgroup of those with chronic hepatitis $\mathrm{C}$, as they are at increased risk of hepatic decompensation, liver failure, and hepatocellular carcinoma. Boceprevir-based triple therapy produced an SVR12 in $67 \%$ of patients with compensated cirrhosis in the present study. Patients with a history or evidence of hepatic decompensation were excluded from this study in accordance with labeling for boceprevir and peginterferon alfa-2a. However, the incidence of SAEs, including anemia and thrombocytopenia, was somewhat higher in patients with cirrhosis than in non-cirrhotic patients, demonstrating that clinicians must monitor the former closely during treatment. The AE burden associated with boceprevir-based triple therapy is increased in patients with cirrhosis, and in particular, in those patients with cirrhosis in combination with a baseline platelet count $<100,000 / \mathrm{mm}^{3}$ and serum albumin level $<35 \mathrm{~g} /$ L [15]. Thus, careful patient selection is necessary when using boceprevir.

In an ideal world, every patient with chronic hepatitis $\mathrm{C}$ would have access to interferon-free regimens; in reality, this is restricted. In Western Europe and North America, publicly funded treatment is available only for patients with advanced liver disease (e.g., Metavir F3-F4) [11], while publicly funded treatment may not be available to any patient in other countries. The first generation of protease inhibitors (PIs) (boceprevir and telaprevir) has been withdrawn from the market in the USA [1], and these are rarely used in Western Europe. Where resources are limited, waiting is the only option as it may be some time before broad access to the new 
combinations is possible on a worldwide scale [16]. Resources are limited in most European countries, even in those that are economically well off, where (with the exception of France) insurance companies restrict the use of interferon-free regimens to patients with advanced liver fibrosis (F3 and F4). Notwithstanding guidance from EASL that boceprevir may need to be used in some settings with limited resources [4], newer DAAs are preferred over first generation PIs, and thus, should be used where available.

Limitations of the TriCo study include the open-label design and the lack of a control group making it difficult to draw direct comparisons with randomized controlled trials in similar populations.

\section{CONCLUSION}

In conclusion, the results of this study demonstrate that an overall SVR rate of $81 \%$ can be achieved with the combination of boceprevir plus peginterferon alfa-2a/ribavirin in treatment-naïve patients with $\mathrm{HCV}$ genotype 1 infection that an SVR12 of 95\% can be achieved in patients with an early response, and that treatment is well tolerated when the restrictions in the label are observed.

\section{ACKNOWLEDGMENTS}

Sponsorship for this study and article processing charges were funded by $F$. Hoffmann-La Roche Ltd, Basel, Switzerland. The authors thank Fernando Tatsch for his contributions to the initiation and setting-up of this study while in the employment of $F$. Hoffmann-La Roche. Support for third-party writing assistance for this manuscript, furnished by Blair Jarvis MSc, ELS, Health
Interactions, was provided by F. Hoffmann-La Roche Ltd, Basel, Switzerland.

All authors had full access to all of the data in this study and take complete responsibility for the integrity of the data and accuracy of the data analysis.

All named authors meet the International Committee of Medical Journal Editors (ICMJE) criteria for authorship for this manuscript, take responsibility for the integrity of the work as a whole, and have given final approval for the version to be published.

Study group. The authors thank the TriCo Study Group investigators: Austria: Andreas Maieron, Michael Gschwantler, Rudolf Stauber, Wolfgang Vogel, Hermann Laferl; Germany: Jörg Petersen, Elmar Zehnter, Gerlinde Teuber, Claus Niederau, Michael Manns; Hungary: Gábor Horváth, Bela Hunyady, Mihály Makara, Gabriella Par, Istvan Tornai; Poland: Krzysztof Simon, Waldemar Halota, Wlodzimierz Mazur, Anna Piekarska, Krzysztof Tomasiewicz; Romania: Liana Gheorghe, Manuela Curescu, Adriana Motoc, Eugen Dumitru; Spain: Miguel Angel Simon Marco, Milagros Testillano Tarrero, Luis Enrique Morano Amado, Francisco Javier Salmerón Escobar.

Disclosures. Peter Ferenci: Global Advisory board: Roche/Genentech, Merck; Advisor: AbbVie, Gilead, Janssen, Achillion; Speaker's bureau: Roche, MSD Austria, Janssen Austria, BMS Austria, Gilead, AbbVie, Boehringer Ingelheim; Unrestricted research grant: Roche Austria. Florin A. Caruntu is an advisor and speaker for AbbVie, BMS, Gilead, Glaxo, Janssen, MSD, and Roche. Gabriella Lengyel has nothing to disclose. Diethelm Messinger is an employee of PROMETRIS GmbH, the clinical research organization providing data 
management and statistical services to Roche. Georgios Bakalos is an employee of $\mathrm{F}$. Hoffmann-La Roche Ltd. Robert Flisiak: Speaker or advisor for AbbVie, Bristol-Myers Squibb, Gilead, Janssen, MSD, Novartis, and Roche.

Compliance with Ethics Guidelines. All procedures followed were in accordance with the ethical standards of the responsible committee on human experimentation (institutional and national) and with the Helsinki Declaration of 1964. Informed consent was obtained from all patients for being included in the study.

Open Access. This article is distributed under the terms of the Creative Commons Attribution-NonCommercial 4.0 International License (http://creativecommons.org/licenses/ by-nc/4.0/), which permits any noncommercial use, distribution, and reproduction in any medium, provided you give appropriate credit to the original author(s) and the source, provide a link to the Creative Commons license, and indicate if changes were made.

\section{REFERENCES}

1. American Association for the Study of Liver Diseases and Infectious Diseases Society of America. Recommendations for testing, managing, and treating hepatitis C. Available at http://www. hcvguidelines.org. Accessed 5 Nov 2015.

2. Afdhal N, Zeuzem S, Kwo P, Chojkier M, Gitlin N, Puoti $M$, et al. Ledipasvir and sofosbuvir for untreated HCV genotype 1 infection. $\mathrm{N}$ Engl J Med. 2014;370(20):1889-98.

3. Afdhal N, Reddy KR, Nelson DR, Lawitz E, Gordon SC, Schiff E, et al. Ledipasvir and sofosbuvir for previously treated HCV genotype 1 infection. N Engl J Med. 2014;370(16):1483-93.

4. EASL. Recommendations on treatment of hepatitis C 2015. J Hepatol 2015;63:199-236.
5. Ferenci P, Bernstein D, Lalezari J, Cohen D, Luo Y, Cooper C, et al. ABT-450/r-ombitasvir and dasabuvir with or without ribavirin for HCV. N Engl J Med. 2014;370(21):1983-92.

6. Kowdley KV, Gordon SC, Reddy KR, Rossaro L, Bernstein DE, Lawitz E, et al. Ledipasvir and sofosbuvir for 8 or 12 weeks for chronic $\mathrm{HCV}$ without cirrhosis. N Engl J Med. 2014;370(20):1879-88.

7. Lawitz E, Sulkowski MS, Ghalib R, Rodriguez-Torres M, Younossi ZM, Corregidor A, et al. Simeprevir plus sofosbuvir, with or without ribavirin, to treat chronic infection with hepatitis $\mathrm{C}$ virus genotype 1 in non-responders to pegylated interferon and ribavirin and treatment-naive patients: the COSMOS randomised study. Lancet. 2014;384(9956):1756-65.

8. Ferenci P, Reddy KR. Impact of HCV protease-inhibitor-based triple therapy for chronic HCV genotype 1 infection. Antivir Ther. 2011;16(8):1187-201.

9. Poordad F, McCone J Jr, Bacon BR, Bruno S, Manns MP, Sulkowski MS, et al. Boceprevir for untreated chronic HCV genotype 1 infection. N Engl J Med. 2011;364(13):1195-206.

10. Mishra P, Murray J, Birnkrant D. Direct-acting antiviral drug approvals for treatment of chronic hepatitis $C$ virus infection: scientific and regulatory approaches to clinical trial designs. Hepatology. 2015;62(4):1298-303.

11. Aronsohn A, Jensen D. Expanding access to hepatitis $\mathrm{C}$ virus care: a call to deconstruct individualized therapy. Hepatology. 2014;59(1):13-5.

12. Jacobson IM, Dore GJ, Foster GR, Fried MW, Radu M, Rafalsky VV, et al. Simeprevir with pegylated interferon alfa 2 a plus ribavirin in treatment-naive patients with chronic hepatitis $\mathrm{C}$ virus genotype 1 infection (QUEST-1): a phase 3, randomised, double-blind, placebo-controlled trial. Lancet. 2014;384(9941):403-13.

13. Manns M, Marcellin P, Poordad F, de Araujo ES, Buti M, Horsmans $Y$, et al. Simeprevir with pegylated interferon alfa $2 \mathrm{a}$ or $2 \mathrm{~b}$ plus ribavirin in treatment-naive patients with chronic hepatitis $\mathrm{C}$ virus genotype 1 infection (QUEST-2): a randomised, double-blind, placebo-controlled phase 3 trial. Lancet. 2014;384(9941):414-26.

14. Ferenci P, Asselah T, Foster GR, Zeuzem S, Sarrazin C, Moreno C, et al. STARTVerso1: a randomized trial of faldaprevir plus pegylated interferon/ ribavirin for chronic HCV genotype-1 infection. J Hepatol. 2015;62:1246-55. 
15. Hezode C, Fontaine H, Dorival C, Zoulim F, Larrey $\mathrm{D}$, Canva V, et al. Effectiveness of telaprevir or boceprevir in treatment-experienced patients with HCV genotype 1 infection and cirrhosis. Gastroenterology. 2014;147(1):132-42.
16. vandeVen N, Fortunak J, Simmons B, Ford N, Cooke GS, Khoo $S$ et al. Minimum target prices for production of direct-acting antivirals and associated diagnostics to combat hepatitis $\mathrm{C}$ virus. Hepatology 2015;61(4):1174-1182. 